\title{
Vegetable fiber as reinforcing elements for cement based composite in housing applications - a Brazilian experience
}

\author{
Viviane da Costa Correia ${ }^{1}$, Sergio Francisco Santos ${ }^{2}$ and Holmer Savastano Junior ${ }^{3}$ \\ ${ }^{1}$ University of São Paulo, Department of Biosystems Engineering - Research Nucleus on Materials for Biosystems, \\ Pirassununga, SP, Brazil \\ ${ }^{2}$ São Paulo State University, Department of Materials and Technology - School of Engineering, Guaratinguetá, SP, Brazil
}

\begin{abstract}
Vegetable fibers are a hierarchical structure material in the macro, micro and nanometric scales that have been used as reinforcement in cementitious materials. In nanoscale, the nanofibrillated cellulose has the advantage of having good mechanical performance and high specific surface, which contributes to improve the adhesion between fiber and matrix. In hybrid reinforcement, with micro and nanofibers, nanofibrillated cellulose forms bonding with the matrix and acts as stress transfer bridges in the nano-cracking with corresponding strengthening of the cementitious composite. Processing has a strong influence on performance of the fiber cement composite. Two fabrication methods were evaluated: (i) slurry dewatering followed by pressing and (ii) extrusion. The extrusion process strongly depends on the rheological characteristics of the fresh cement material but it can better organize the microstructure of the fiber cement due to the partial orientation of the fibers in the extruder direction. Curing process also plays a key role in the performance of the final product. Accelerated carbonation at early age is a promising technology and a strategy to mitigate the durability problems with the composite materials; it decreases porosity, promotes a higher density in the interface guarantying a good fiber-matrix adhesion and a better mechanical behavior. Alternative $\mathrm{MgO}-\mathrm{SiO} 2$ clinker free binder is also presented as a suitable alternative to cementitious products reinforced with cellulosic pulps. Finally, mechanical behavior of fiber cement under flexural loading is evaluated by modulus of rupture, fracture toughness, the initial crack growth resistance in cement matrix, and fracture energy that is obtained to evaluate the influence of toughening mechanisms promoted by fibers, such as pullout and bridging, on the mechanical performance of the composites. Degradation during the service life is also crucial for the evaluation of the durability of the resulting materials and components in real applications exposed to different environmental conditions as roofing, partitioning or ceiling elements. It can be concluded that more sustainable and high performance components based on engineered natural raw materials for civil construction can bring valuable contributions for the affordable housing in particular to developing region.
\end{abstract}

\section{Introduction}

Fiber-cement is a cement-based material with mineral additions (pozzolans and/or carbonates), without aggregates and reinforced with fibers distributed through the matrix. Normally, in the Brazilian market, fiber-cement is produced with a Portland cement matrix and synthetic fiber combined with cellulose pulp as reinforcement. Hatschek is the most popular processing method followed by curing in saturated air conditions. Asbestos fibers are still used for some products but their application is being progressively reduced in many regions due to occupancy health concerns. Fiber-cement is a versatile material used in different manufacture processing of construction industry products such as corrugated sheets for roofing, water tanks, tubes and flat boards. These products can be applied in the countryside, industries, residences, non-residences and for other applications such as furniture and decoration products [1]-[3].

Fiber-cement has been largely produced since the beginning of the last century with the advent of the Hatschek process. Since 1938, roofing tiles made of fibercement have been used in Brazil. Back to the mid-1960s, fiber-cement already had $25 \%$ of the roofing area per year in the country. However, it was in the early 1970s that fiber-cement was established in the Brazilian civil construction industry, which continues until now [3]. 
In Brazil, fiber-cement products are considered one of the best solutions for housing destined to the population with lower income. It is a lightweight product and have lower cost (taking in account the structure required) compared to other conventional constructive solutions for roofs and flat plates for walls [3]-[4].

Vegetable fibers, as reinforcement of fragile matrices based on inorganic materials, have attracted great interest due their low cost, availability, energy saving and environmental preservation. In the USA market, the main production of fiber-cement is based on autoclaved products reinforced with cellulosic pulp [4]-[6].

\section{Vegetable fibers}

In Australia, Commonwealth Scientific and Industrial Research Organization (CSIRO) in the early 1970s had active research programs in studying ways to utilize wood fibers as reinforcement in a broad range of composite materials and in modification of the surface and malleability of wood pulp fibers to make them more compatible with various organic and inorganic matrices. The systematic study of the use of vegetable fibers for reinforcement began in England in 1970 [5]. In Brazil, one of the pioneering researches was carried out by the Center for Research and Development (Ceped) in Camaçari, Bahia, which started in 1980 [7]. These materials offer durability and resilience, even in extreme loading conditions, and contribute to infrastructure sustainability via reduced repair events and extended service life. The role of interfaces in relation to design at all scales area corresponds the composites reinforced with vegetable fibers, which have a hierarchical structure and are more sustainable compared to synthetic fibers that are commonly used in the cement industry, such as glass and polypropylene fibers.

Agopyan et al. [3] studied the use of vegetable fibers as reinforcement of fragile matrices and related about 20 fibers potentially useful for the civil construction. The most adequate fibers were selected based on their mechanical properties (tensile strength, Young's modulus and elongation at break), physical characteristics, aspect ratio, cultivation, cost and durability in the natural environment. Softwood pulps, especially those with low lignin content, are already in current use in the Brazilian cement industry. Additionally, hardwood pulps have been studies in countries where their production is abundant [8]-[9].

In addition to cellulosic pulp, vegetable fibers at the nanoscale have also been used as reinforcement for cementitious composites, given that some authors report that nanofibers act as transfer bridges of cracks, which begin at the nanometric scale [10]-[14].

Figure 1 shows an example of bamboo fibers in different scales (macro (a), micro (b) and nano (c)) and their respective micrographs, showing the difference in the morphology of these fibers.

Demonstrating utility of curauá fiber as engineered cementitious composites (ECC) reinforcement would greatly expand the range of applications and would represent a significant step toward the popular use of renewable vegetable fiber in materials mainly for construction applications. The curauá-ECC is well suited to building cladding and façade applications, where lightweight and thermal regulation properties are important. The inherently porous natural fibers provide curauá-ECC with a low density that is theoretically beneficial for both of these aspects and the strain-hardening behavior provides an additional bonus of material durability [15].

Ardanuy et al. [16] used $3.3 \%$ (by mass) of nanofibrillated cellulose from sisal as reinforcement of mortar in comparison of mortar reinforced with the same level of cellulosic pulp. The authors reported an increase of the $26.4 \%$ in the flexural strength and $41.5 \%$ in the modulus of elasticity in the mortar reinforced with nanofibrillated cellulose in comparison to mortar reinforced with the pulp. According to the authors, these results are due to the fact that the nanofibrillated cellulose had higher stiffness and higher intrinsic resistance compared to cellulosic pulp. According to Ardanuy et al. [16], the high specific surface area of the nanofibrillated cellulose promotes a better fibermatrix bonding, as well as the increase of the hydroxyl groups available in the cellulose to form hydrogen bonds with the cementitious matrix.

Thomson et al. [17]produced hybrid composites, by the slurry dewatering followed by pressing process, reinforced with $8 \%$ of cellulosic pulp and the contents of $0.5 \%, 1.0 \%$ and $2.0 \%$ of nanocrystalline cellulose to define the best content of nano reinforcement. The mechanical results showed the increase of the modulus of rupture of composites with up to $0.5 \%$ of nanofibers and the modulus of elasticity increased with nanofibers content of $2.0 \%$.

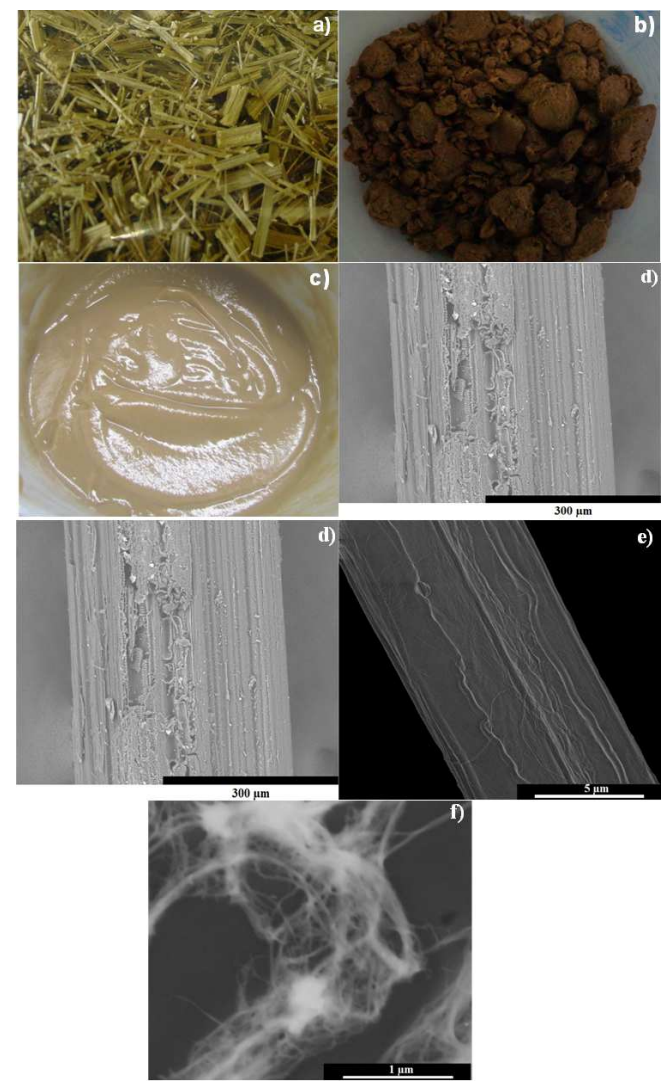

Fig. 1. Bamboo fibers at macro ((a), (d)), micro (cellulosic pulp) ((b), (e)), and nano (nanofibrillated cellulose) scales ((c), (f)) [18]. 
The results of these studies confirm that the use of nanometric fibers and a hybrid reinforcement is effective for increasing the mechanical properties of cementitious materials.

\section{Fiber-cement manufacturing processes}

\subsection{Hatschek Process}

The Hatschek is the most commonly used process for the production of fiber-cement flat and corrugated plates for application in the civil construction industry. The raw materials commonly used in the process are Portland cement, carbonaceous material, silica fume, vegetable fibers in the form of pulp and polymeric fibers (in replacement to the asbestos fiber).

The mainly stages in the Hatschek process are showed in Figure 2. The first step is to prepare the slurry (1), which consists of mixing an adequate proportion of solid materials, with water in a low solid concentration (approximately $20 \%$ of total mass). Portland cement (2), reinforcement fibers (3), cellulose fibers, limestone filler (4) and water (5) are the most commonly used materials by the fiber cement technology. The slurry is then transported to the vats (6) with sieve cylinders (7) where wet solid material is deposited. After, the running felt (8) removes the material from the sieve cylinders, thus, forming a green lamina. Vacuum (9) is applied to remove water from the lamina before it is transferred to the formation cylinder (10) where the stacking is performed. Finally, the green sheet (F) is cut (11), shaped (corrugated sheets and accessories, e. g.) (12) and submitted to curing [19]-[21].

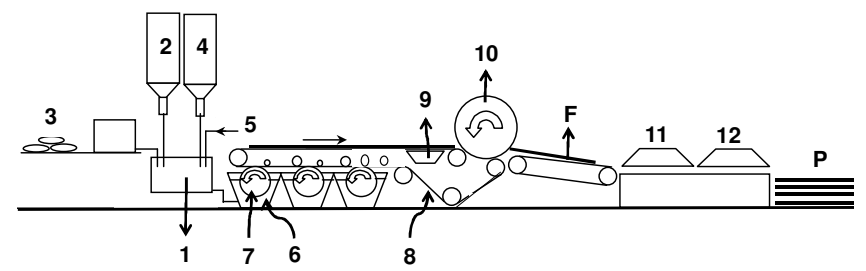

Fig. 2. Schematic drawing of a typical Hatschek process. In this figure $\mathrm{F}$ is the green sheet fiber cement and $\mathrm{P}$ is a final product (Adapted from Dias et al., [19]; Correia et al., [20]).

During the process the fibers need to meet several variables of the production process, such as: do not sediment and agglomerate when it is mixed with the cement and additions in aqueous suspension; it should be capable of retaining fines during the filtering step and do not damage the felt. The fibers also cannot present a risk to the health of workers and users. In addition, the fibers must be able to achieve components with good mechanical performance and durability.

The products manufactured by the Hatschek process are corrugated roofing tiles, roof ridges, flashings and hips), flat boards, as well as structural roof tiles for large gaps.

\subsection{Extrusion Process}

The extrusion method displays versatility in the preparation of varied cross-sectional configuration building components, not limited to plates, as in many conventional processes. The shearing and compression forces involved in extrusion process makes the composite more homogeneous and with a better distribution of the fibers in the most favorable direction in order to provide best performance of the fibers, especially in the case of nanofibrillated cellulose. Additionally, extrusion is an efficient process that has the following aspects: the use of a relatively simple equipment; low energy consumption and low water quantity; low investment amount to implement a production line [22][23]. Figure 3 illustrates the production of fiber-cement by the extrusion method.

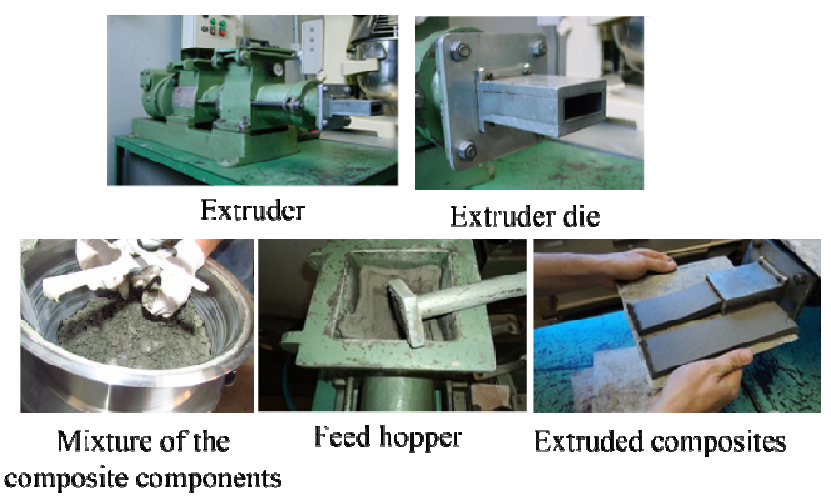

Fig. 3. Single screw extruder used in the extrusion process and the production steps of composite.

The manufacturing of fiber-cement products, in industrial scale, is generally applying the Hatschek process, although this method requires much higher financial investments for a production line. The extrusion process is an alternative process for manufacturing fiber-cement products, for some specific applications such as: tubes, tiles and sidings. The extruder used in the ceramics industry can be adapted for the production of fiber-cement [24].

However, according to Kuder et al. [25], some challenges related to the rheological aspects of the extrusion process require to be studied and improved, such as mixing of raw materials that is important and complex dynamics process related to rheological properties as well as of chemical and physical interactions between the components. For example, the mixing interferes in the agitation of the powders with different bulk densities may result in migration of smaller particles downwards and of larger ones upwards. Besides, the extrusion process requires to study the application of rheological modifiers to adjust the flow behavior (viscosity) and to ensure that the liquid and solid phases of the extrudate do not separated during extrusion, such as those based on high-molecular weight synthetic copolymers, starch ethers, polyacrylamides and clay binders.

\section{Accelerated carbonation curing}

The main objective of fiber-cement curing thru accelerated carbonation is to minimize the degradation of lignocellulosic fibers in cement matrix and to maintain 
mechanical performance of composites when they are under aggressive weather conditions [26]-[28].

Tonoli et al. [29] indicated the use of accelerated carbonation after the initial curing of fiber-cement tiles as an effective procedure to minimize the degradation suffered by lignocellulosic fibers. The authors studied the mechanical and physical characteristics of carbonated fibercement. The maximum load and toughness of the tiles increased by around $25 \%$ and $80 \%$ respectively. These results were achieved due to the adoption of accelerated carbonation curing. Water absorption and apparent porosity of composites decreased, while bulk density increased indicating the densification of the material.

Almeida et al. [26] evaluated the effects of accelerated carbonation on the mechanical and physical performance and microstructure of fiber-cement reinforced with only cellulosic pulps at the initial ages, during and after the hydration process. The authors also evaluated the effects of accelerated carbonation in fiber-cement reinforced with cellulosic pulps at the initial ages of hydration, after 200 and 400 soak and dry cycles, and after one year of natural aging. According to the authors, the fiber-cement showed a significant decrease in $\mathrm{Ca}(\mathrm{OH})_{2}$ and a significant increase in $\mathrm{CaCO}_{3}$ and, consequently, low porosity, high density, good fiber-matrix interface and good mechanical performance, according to Figure 4.

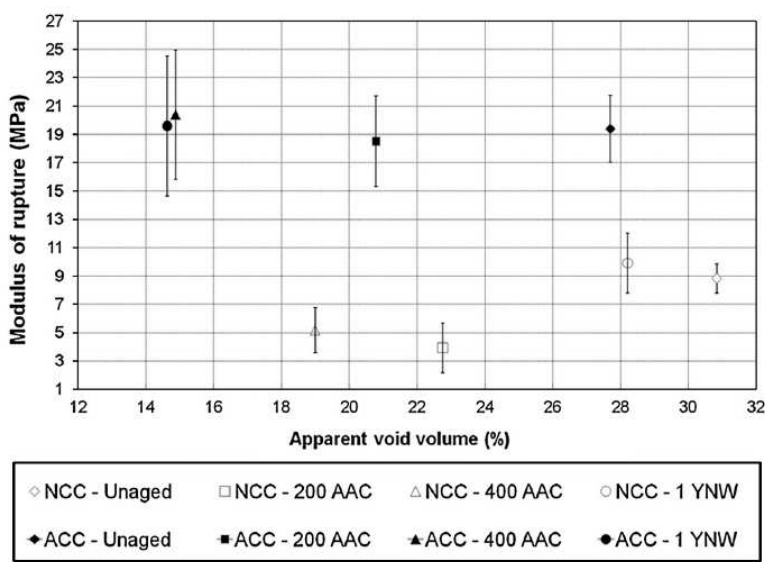

Fig. 4. Average values of mechanical properties vs. apparent void volume (AVV): and modulus of rupture (MOR) of cement based composites: non-carbonated (NCC), carbonated (ACC), after 200 and 400 soak and dry cycles, and after one year of natural aging (YNW).

Santos et al. [28] investigated the effects of supercritical carbonation on extruded fiber-cement reinforced with lignocellulosic fibers (eucalyptus bleached pulp and sisal fibers) after three days of curing. The cure with supercritical carbonation at early ages involves a different chemical kinetics of conventional accelerated carbonation using $\mathrm{CO}_{2}$ gas, because it uses $100 \%$ of liquid $\mathrm{CO}_{2}$. After 200 immersion and drying cycles, the average fracture energy of the non-carbonated and carbonated composites decreased $56 \%$ and $28 \%$, respectively.

Besides the accelerated carbonation curing enhances the durability of cementitious composites reinforced with vegetable fibers, this cure favors the increase of mechanical performance of hybrid composites reinforced with micro and nanofibers. Correia et al. (2015) produced cementitious composites with hybrid reinforcement at micro and nano scales $(8 \%$ pulp $+1 \%$ nanofibrillated cellulose) compared to composites reinforced with only pulp (9\% pulp) and observed the effect of accelerated carbonation curing on the physical and mechanical properties of these composites. The authors observed that accelerated carbonation curing contributed to the improvement in the mechanical performance of composites with and without nanofibers, as presented in Figure 5.

The accelerated carbonation curing favored the better performance of the matrix and of the composite in postcracked condition. This result is attributed to the reactions that occur during carbonation, in which there is the precipitation of calcium carbonate $\left(\mathrm{CaCO}_{3}\right)$ into the pores of the matrix. As calcium carbonate is denser than calcium hydroxide, there is greater densification of the matrix, reducing pores and improving fiber-matrix bonds and, consequently, improving the mechanical performance of the composite.

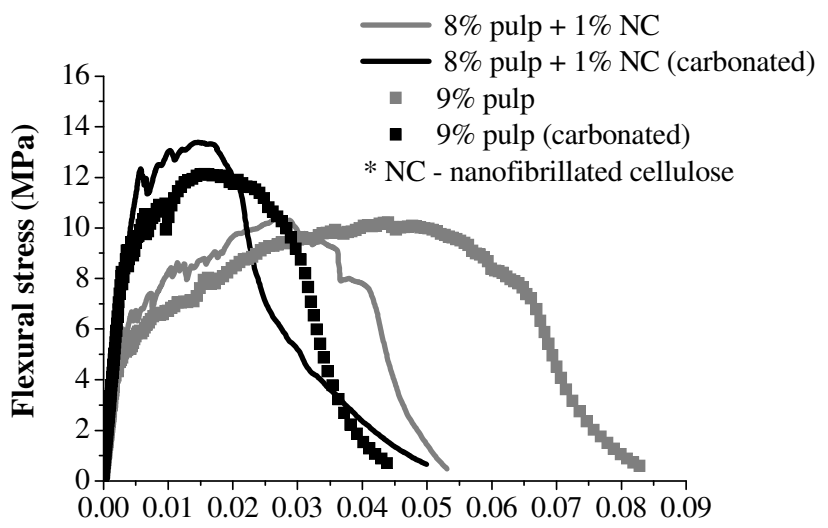

Specific Deformation $(\mathbf{m m} / \mathbf{m m})$

Fig. 5. Typical stress $x$ strain curves at under flexure tests of the composites reinforced with $8 \%$ of eucalyptus pulp $+1 \% \mathrm{NC}$, and $9 \%$ of eucalyptus pulp in carbonated and non-carbonated conditions.

\section{Magnesium oxide cement}

New types of cement as magnesium oxysulfate (MOS) cements have been successfully used to prevent cellulosic fibers degradation over time. However, the mechanical results of this new kind of cement are far lower than those obtained with Portland cement products. Besides MOS cement presents leaching problems with time. To solve these inconveniencies, a new type of magnesia cement for the production of fiber-cement elements from calcination of $\mathrm{MgO}$ powder and reactive $\mathrm{SiO}_{2}\left(\mathrm{MgO}-\mathrm{SiO}_{2}\right.$ cement $)$ has been developed. Over the last decade, many authors have studied this $\mathrm{MgO}-\mathrm{SiO}_{2}$ cement, which hydrates to form magnesium silicate hydrated (M-S-H) gel and magnesium hydroxide $(\mathrm{MH})$, bringing as a result a binding material with low alkalinity and excellent mechanical properties. This cement also has the advantage of offering a chemical composition with irrelevant amounts of calcium, thus avoiding fiber mineralization [30]-[31]. 
Figure 6 shows the compressive strength results. At 7 days, there is a slight enhancement of the mechanical strength with the increase of the $\mathrm{MgO}$ in the samples. This difference is statistically significant when the $\mathrm{MgO}$ content varies from 60 to $70 \%$, but at 7 days of curing the samples containing 50 and $60 \%$ of $\mathrm{MgO}$ and those with 70 and $80 \%$ each have statistically similar values. However, at 28 days, all the formulations containing $\mathrm{MgO}$ have at least equivalent strength to the control samples. It is also remarkable that the $\mathrm{MgO} \backslash S i O_{2}$ samples present a strength improvement from 7 to 28 days for every formulation, in contrast to the control samples which have no statistically considerable variation [31].

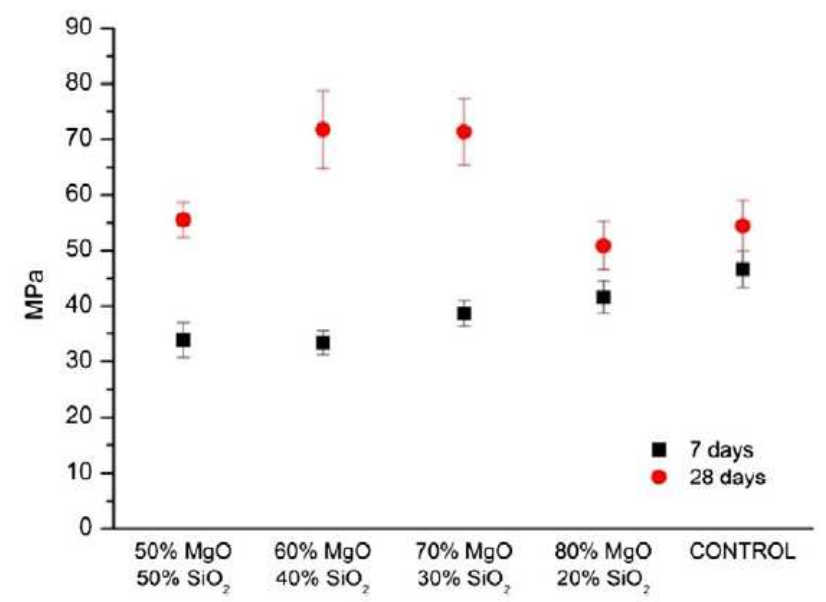

Fig. 6. Axial compressive strength of different $\mathrm{MgOlSiO}_{2}$ pastes and control samples (100\% high initial strength Portland cement, CP V-ARI, according to Brazilian Standards NBR 5733) at 7 and 28 days. (Mármol et al., 2016).

Therefore, the use of $\mathrm{MgO}-\mathrm{SiO}_{2}$ is presented as a suitable alternative to cementitious products reinforced with cellulosic pulps with potential application in civil construction in view of acceptable performance under binding solicitations and since no appreciable degradation of the fibers takes places after 200 soak and dry accelerated ageing cycles. The $60 \mathrm{wt} \% \mathrm{MgO}-40 \mathrm{wt} \% \mathrm{SiO}_{2}$ system is presented as the optimal formulation, since it is the least alkaline binder with high mechanical strength. Bending tests on pastes reinforced with cellulosic pulps proved the efficiency of this binder, which preserves the reinforcing capacity of the fibers much better than Portland cement pastes after 200 cycles of accelerated ageing [30-31].

\section{Final remarks}

The high availability of vegetable fibers in Brazil and in other developing countries in the world justifies the research for the development of new and more sustainable building materials reinforced with vegetable fibers in fragile matrix based on cement. The physical and mechanical characteristics of the vegetable fibers make them a promising material for the partial or total substitution of the synthetic fibers as reinforcement in inorganic matrices.
However, due to low durability of the vegetable fibers in a highly alkaline environment, such as the cementitious matrix, alternative matrices and accelerated carbonation have been developed to enable the production of a more sustainable material with good physical and mechanical performance and with improved durability. That is the case of magnesium based cement products reinforced with cellulosic pulps. Thus, materials reinforced with vegetable fibers are technically possible to be produced and economically viable in regions where the raw material is abundant.

\section{Acknowledgements}

The authors would like to acknowledge financial support from the Fundação de Amparo à Pesquisa do Estado de São Paulo, FAPESP, (Grants: 2008/04769-9, 2009/10614-0, 2009/17293-5; 2010/16524-0, 22011/01128-5, 2012/51467$3,2013 / 23810-8$ and 2015/21079-0) and the Conselho Nacional de Desenvolvimento Científico e Tecnológico, CNPq, (Grants: 472133/2009-8, 305792/2009-1, 142082/2011-2 and 312151/2016-0).

\section{References}

[1] M. Ardanuy, J. Claramunt, R.D. Tôledo Filho, Constr. Build. Mater. 79, 115 (2015)

[2] A. Bentur, S. Mindess, Fibre Reinforced Cementitious Composites (Taylor \& Francis, 2007)

[3] V. Agopyan, H. Savastano Jr, V.M. John, M.A. Cincotto, Cement Concrete Comp. 27, 527 (2005)

[4] S.F. Santos, G.H.D. Tonoli, J.E.B. Mejia, J. Fiorelli, H. Savastano Jr, H, Materiales de Construcción 65, 317 (2015)

[5] R. Coutts, Cement Concrete Comp. 27518 (2005)

[6] O. Onuaguluchi, N. Banthia, Cement Concrete Comp. 68, 96 (2016)

[7] CEPED - Centro de Pesquisas e Desenvolvimento da Bahia. Cartilha para fabricação de telhão em argamassa armada (BNH, 1985) (In Portuguese)

[8] G.H.D. Tonoli, U.P. Rodrigues Filho, H. Savastano Jr, J. Bras, M.N. Belgacem, F.A. Rocco Lahr, Compos. Part. A-Appl. S. 40, 2046 (2009)

[9] G.H.D. Tonoli, E. Fuente, C. Monte, H. Savastano Jr, F.A. Rocco Lahr, A. Blanco, Cement Concrete Res. 39, 1017 (2009)

[10] O. Galao, F.J. Baeza, E. Zornoza, P. Garcés, Cement Concrete Comp. 46, 90 (2014)

[11] C.G. Hoyos, E. Cristia, A. Vázquez, Mater. Design. 51, 810 (2013)

[12] G. Yakovlev, J. Kerienè, A. Gailius, I. Girniene, Mater. Sci. 12, 147 (2006)

[13] J.M. Makar, J.C. Margeson, J. Luh, Carbon nanotube/cement composite - early results and potential applications (International Conference on Construction Materials: Performance, Innovation and Structural Implications, 2005).

[14] G.Y. Li, P.M Wang, X. Zhao, Carbon. 43, 1239 (2005) 
[15] D.G. Soltan, P. Neves, A. Olvera, H. Savastano Jr, V.C. Li, Ind. Crop. Prod. 1031 (2017)

[16] M. Ardanuy, J. Claramunt, R. Arévalo, F. Parés, BioResources. 733883 (2012)

[17] S.L. Thomson, D.J. O'Callaghan, J.A. Westland, B. Su, Method of making a fiber cement board with improved properties of the product. Patent US 2010/0162926 AL, (2010)

[18] V.C.,Correia, V. Santos, L.B. Rodier, K. Ghavami, H. Savastano Jr, Green. Mater. 4, 41 (2016)

[19] C. M.R. Dias, H. Savastano Jr., V. M. John, Constr. Build. Mater. 24, 140 (2010)

[20] V.C. Correia, S.F. Santos, H. Savastano Jr, World Academy of Science, Engineering and Technology: International Journal of Civil, Architectural, Structural and Construction Engineering 9, 7 (2015)

[21] V.C. Correia, S.F. Santos, G.H.D Tonoli, H. Savastano $\mathrm{Jr}$, Characterization of vegetable fibers and their application in cementitious composites (Woodhead Publishing, 2016)

[22] H. Takashima, K. Miyagay, T. Hashida, V. C. Li, Eng. Fract. Mech. 70, 853 (2003)
[23] R.S. Teixeira, G.H.D. Tonoli, S.F. Santos, J. Fiorelli, H. Savastano Jr, F.A.R. Lahr, Key. Eng. Mat. 517, 450 (2012)

[24] G.G. Horst, Extrusion of FRC products: technology and practical aspects (Inorganic-Bonded wood and fiber composites materials Conference, 2002)

[25] K.G. Kuder, S.P. Shah, Constr. Build. Mater. 24, 181 (2010)

[26]E.F.S. Almeida, G.H.D. Tonoli, S.F. Santos, H. Savastano Jr, Cement Concrete Comp. 42, 49 (2013)

[27] V.D. Pizzol, L.M. Mendes, L. Frezzatti, H. Savastano Jr, G.H.D. Tonoli, Miner. Eng. 59, 101 (2014)

[28] S. F. Santos, R. Schmidt, A.E.F.S. Almeida, G.H.D. Tonoli, H. Savastano Jr, Cement Concrete Comp. 56, $84(2015)$

[29] G.H.D. Tonoli, S.F. Santos, A.P. Joaquim, H. Savastano Jr, Constr. Build. Mater. 24, 193 (2010)

[30] G. Mármol, H. Savastano Jr, Cement Concrete Comp. 80, 258 (2017)

[31] G. Mármol, H. Savastano Jr, M.M Tashima, J.L. Provis, Mater. Design 105, 251 (2016) 